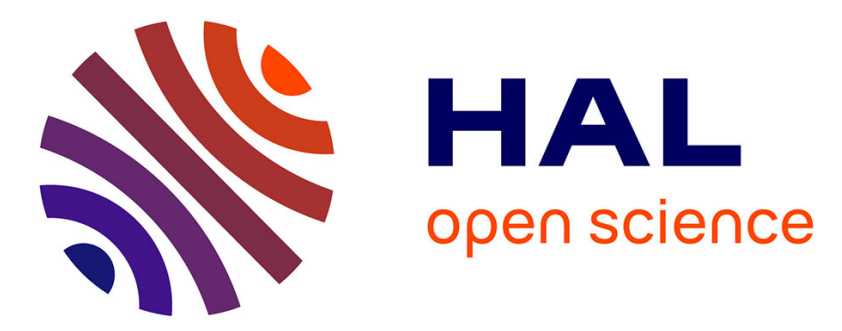

\title{
Some simulations of the effect of varying excitation parameters on the transients of reed instruments
}

Fabrice Silva, Vincent Debut, Philippe Guillemain, Jean Kergomard, Christophe Vergez

\section{- To cite this version:}

Fabrice Silva, Vincent Debut, Philippe Guillemain, Jean Kergomard, Christophe Vergez. Some simulations of the effect of varying excitation parameters on the transients of reed instruments. 21st International Congress on Acoustics (ICA 2013), Jun 2013, Montréal, Canada. pp.4aMU4, 10.1121/1.4799457] . hal-01309177

\section{HAL Id: hal-01309177 \\ https://hal.science/hal-01309177}

Submitted on 29 Apr 2016

HAL is a multi-disciplinary open access archive for the deposit and dissemination of scientific research documents, whether they are published or not. The documents may come from teaching and research institutions in France or abroad, or from public or private research centers.
L'archive ouverte pluridisciplinaire HAL, est destinée au dépôt et à la diffusion de documents scientifiques de niveau recherche, publiés ou non, émanant des établissements d'enseignement et de recherche français ou étrangers, des laboratoires publics ou privés. 


\title{
Proceedings of Meetings on Acoustics
}
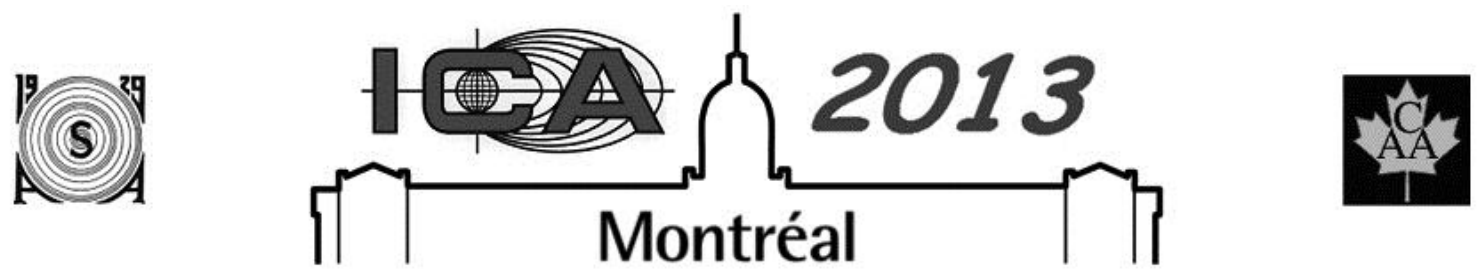

\author{
ICA 2013 Montreal \\ Montreal, Canada
}

2 - 7 June 2013

Musical Acoustics

Session 4aMU: Transient Phenomena in Wind Instruments: Experiments and Time Domain Modeling

\section{4aMU4. Some simulations of the effect of varying excitation parameters on the transients of reed instruments}

Fabrice Silva, Vincent Debut, Philippe Guillemain, Jean Kergomard* and Christophe Vergez

\begin{abstract}
*Corresponding author's address: Laboratoire de Mécanique et d'Acoustique, CNRS-LMA, Marseille, 13402, France, France, kergomard@Ima.cnrs-mrs.fr

This paper considers the simulation of self-sustained oscillations in reed and brass instruments, based on a compact continuous-time formulation of the sound production mechanism. The control parameters such as the mouth pressure and the player's embouchure, but also the acoustic resonator and the reed may vary with respect to time, allowing the analysis of transient and non-stationary phenomena like changes of regime. A particular attention is first given to staccato notes, with comparison of the evolution of the instantaneous frequency in simulations to theoretical and experimental results. This shows the importance of using realistic control parameters on the onset of the oscillations. When the acoustic resonator is modelled using a modal expansion with non-stationary resonance frequencies and damping, it is also possible to simulate and study slurs and musical effects like the wah-wah, gaining some insight on the mechanisms involved.
\end{abstract}

Published by the Acoustical Society of America through the American Institute of Physics 


\section{INTRODUCTION}

In sound analysis or synthesis, transients are necessary in the sense that they carry information useful to listener to identify the instrument and to perceive the musician intention. Timedomain simulation is helpful in understanding the relation between variation in control parameters and characteristics of the resulting sound. The present paper considers the time-domain simulation using modal expansion for the behaviour of the passive parts of the reed instruments, i.e. the reed and the resonator (the nonlinear part corresponding to the coupling between airflow and the reed acting as a valve). This allows taking into account in a simple way the variation of the control parameters, such as the mouth pressure and the player's embouchure, but also the acoustic resonator and the reed whose parameters may vary with respect to time, allowing the analysis of transient and non-stationary phenomena like changes of regime.

In the assumption of linear acoustics, a resonator can be fully described by its input impedance, and this quantity can be expanded into modes of the resonator. This leads to the solving of a set of Ordinary Differential Equations. Modal analysis is widely used in musical acoustics to analyse and reproduce the vibration of complex vibrating structures, but few applications have been treated for self-sustained instruments (Ref. [1] for the study of the bowed string, Ref. [2] for sound synthesis, and Ref. [3] for a dynamical system approach).

We first present the modelling of the problem, based upon a classical description of the different parts of the instrument, then the time domain simulation, and present two examples: the first one if the mouth pressure rise in clarinet-like instrument, and the effect of the speed of the rise on the resulting attack. The second one concerns brass instruments, first slurred transients obtained when the natural frequencies of the lips are varying during the sound for a given length of the resonator, then the wah-wah effect simulating dynamic variation of the input impedance of the trumpet.

\section{MODELLING}

The elementary model used by many authors (see e.g. [4]) assumes the representation of the sound production mechanism by an acoustic resonator and an exciter, and their mutual coupling. This leads to a system of three equations modelling the reed (cane or lip reed) motion, the acoustic waves in the bore of the instrument and the flow of air through the reed channel. Those are formulated using a control-theory approach, defining a state vector $X(t)$ and its dynamics $d X / d t=f(X, t, \ldots)$. Hereafter are described the partial state vector associated with each part of the system:

$$
X=\left[X_{r}, X_{a}, X_{f}\right]^{T}
$$

\section{Reed motion}

Extending previous models such as the massless reed [5] or the single d.o.f. [6], a general class of transfer function is considered, relating the reed channel opening $h(t)$ to the driving term, here the pressure difference $\Delta p(t)$ :

$$
\frac{d^{N} h}{d t^{N}} \ldots+a_{N-1} \frac{d h}{d t}+a_{N}\left(h(t)-h_{0}\right)=b_{0} \frac{d^{M} \Delta p}{d t^{M}}+\ldots+b_{M-1} \frac{d \Delta p}{d t}+b_{M} \Delta p(t)
$$

with $M \leq N$, or, using the Laplace transform

$$
\frac{H(s)}{\Delta P(s)}=\frac{\sum_{m=0}^{M} b_{m} s^{M-m}}{\sum_{=0}^{N} a_{n} s^{N-n}}
$$

where $s$ is the Laplace variable (usually evaluated on the frequency axis $s=j \omega$ ), and $a_{0}=1$. This simplifies for the single d.o.f. reed with natural angular frequency $\omega_{r}$, damping $q_{r}$ and stiffness 
$K_{r}$ to $N=2, M=0$ and $a_{1}=q_{r} \omega_{r}, a_{2}=\omega_{r}^{2}$ and $b_{0}=\omega_{r}^{2} / K_{r}$. The observable canonical form is adopted, with the partial state vector:

$$
X_{r}=\left[h(t), \frac{d h}{d t}, \ldots, \frac{d^{N-1} h}{d t^{N-1}}\right]^{T} .
$$

Note also that refinements such as beating reed are handled using contact forces as additional driving terms.

\section{Acoustic resonator}

While it is possible to fine-grainly describe the pecularities of the geometry and of the phenomena at the open tone holes or at the bell, the focus is here given to the results of those on the input impedance of the bore. This approach is valid since the valve-bore coupling is localised at the entrance of the bore. Furthermore, the input impedance is parametrised in order to avoid convolution with a long tailed impulse response. The mouthpiece pressure $p(t)$ is expanded as a sum of components $p_{n}(t)$ defined by the modal expansion of the input impedance:

$$
Z_{e}(s)=\frac{P(s)}{U(s)}=\sum_{n} \frac{C_{n}}{s-s_{n}} \Leftrightarrow p(t)=\sum_{n} p_{n}(t) \text { with } \frac{d p_{n}}{d t}=C_{n} u(t)+s_{n} p_{n}(t) .
$$

Poles $s_{n}$ and residues $C_{n}$ can be derived analytically for simple models [7], from numerical identification on a measured input impedance or estimated through a spatial modal analysis (with observation at the bore entrance). Hermitian symmetry implies real or complex conjugates poles (and residues), so that

$$
p(t)=\sum_{\mathfrak{S m}\left(s_{n}\right)>0} 2 \Re \mathfrak{R}\left(p_{n}(t)\right)+\sum_{s_{n} \in \mathbb{R}} p_{n}(t) .
$$

The partial state vector thus contains the components $p_{n}(t)$ such that $\Im \mathfrak{m}\left(s_{n}(t)\right) \geq 0$, and its dynamics is given by Eq. (5).

\section{Airflow}

According to Hirchberg [5], the airflow through the reed channel $u(t)$ can be described by a stationnary expression based on the Bernoulli theorem:

$$
u(t)=h(t) \sqrt{\frac{2 \Delta p(t)}{\rho}}
$$

with $\rho$ the air density. Within this approximation, the flow rate $u(t)$ is a simple observable so that the partial state vector related to fluid mechanics is empty. Reed motion induced flow only adds a term in the previous expression, and a partial state vector $X_{f l}$ appears if an instationnary flow description is considered.

\section{Time-Domain SIMUlation}

\section{ODE integration}

Eqs. (2), (5) and (7) define a continuous-time formulation that do not require to be transposed to the discrete-time domain. In fact a wide family of Ordinary Differential Equations (ODE) solvers are able to handle such a formulation, allowing extra precautions when approching singular points such as instants when the system becomes stiff or leaves this property. When considerig stability of the scheme, the adaptative step-size and/or order-size provide a deep advantage in comparison with fixed step-size scheme like Euler method for instance. The following integra-

tors have been tested in the present study: 
Explicit Euler method: the bounded stability region requires small time steps. For usual audio sampling frequencies, this condition forbids the explicit single-step method, leading to instability and explosion of the computed solution. Practically, the sampling frequency can be increased (by a factor $M$ ), it is quite usual for the time step to be about $0.01 / f_{s}(M=100$ intermediate steps between samples at the usual audio sampling frequency $f_{s}=44.1 \mathrm{kHz}$ ). The result is then obtained discarding the intermediate steps, as in the following RungeKutta methods.

Explicit Runge-Kutta methods of order 5(4) and 8(5,3) perform adaptive step size to bound the local truncation error. As in the Euler integrator, the intermediate steps used to obtain the high order are discarded.

VODE and LSODA are multistep methods that re-use previous steps to gain efficiency instead of computing and discarding intermediate steps. They are also variable-order and adaptive step size, and can use both implicit Adams-Moulton methods (AM) or Backward differentiation formulas (BDF) depending on whether the problem is locally stiff or not. LSODA has the advantage of automatically performing the switch between the two methods when stiffness has been detected.

\section{Time-varying control parameters}

Simulation requires that the control parameters are not oversimplified in order for the results to sound perceptively natural. As noted in [8] and also in [9] on clarinet and [10] on brass instruments, it is essential to understand how to perform starting transients and transition between slurred notes. The current code has been designed to allow the definition of time-variable mouth pressure and reed channel opening at rest, but also to dynamically change the reed transfer function and the input impedance using coefficients $a_{n}$ and $b_{m}$, poles $s_{n}$ and residues $C_{n}$ that are allowed to change with respect to time. This involves using academic profiles such as step or smoothed steps, measured mouth pressure or even interpolation between two configurations of the acoustic resonator. The continuous-time domain formulation is preserved through the approximation of sampled signals by cubic spline if needed. Results below will present a few simulations using this process.

\section{RESULTS}

\section{Mouth pressure rise and quality of the attack}

Previous studies [11, 12] showed how the time needed for setting the mouth pressure to its steady value affects the oscillation growth. For slow rise (about $10 \mathrm{~ms}$ ), there is an exponential growth of the fundamental frequency partial that only transfer some energy to the higher harmonics when saturating (i.e. when the nonlinearity of the airflow relationship gets involved). On the contrary, the quickly rising input (less than $1 \mathrm{~ms}$ ) distributes energy amongst all the resonances before mode-locking ensures reorganisation into partials, as shown by Debut [11] defining master and slave components. These results are extended here by simulating the attack of a $50 \mathrm{~cm}$ long cylinder mode (with radius $7 \mathrm{~mm}$, truncated to 8 modes) with a cane reed $\left(\omega_{r}=2 \pi \times 1.5 \mathrm{kHz}, q_{r}=.4\right.$ and $K_{r}=0.5 \mathrm{GPa} / \mathrm{m}^{2}$, aperture at rest $\left.7 \mathrm{~mm}^{2}\right)$ for mouth pressure growing from 0 to $1708 \mathrm{~Pa}$ with various rise time.

Signals on Fig. 1 show an apparent delay in the start of the sound for rise times greater than $5 \mathrm{~ms}$. However, the amplitude extraction evidences that all oscillations have exponential growth with a time constant independant of the rise time before reaching the steady state. Note that the latter seems also to be the same for all the simulations, even for smaller rise time. 

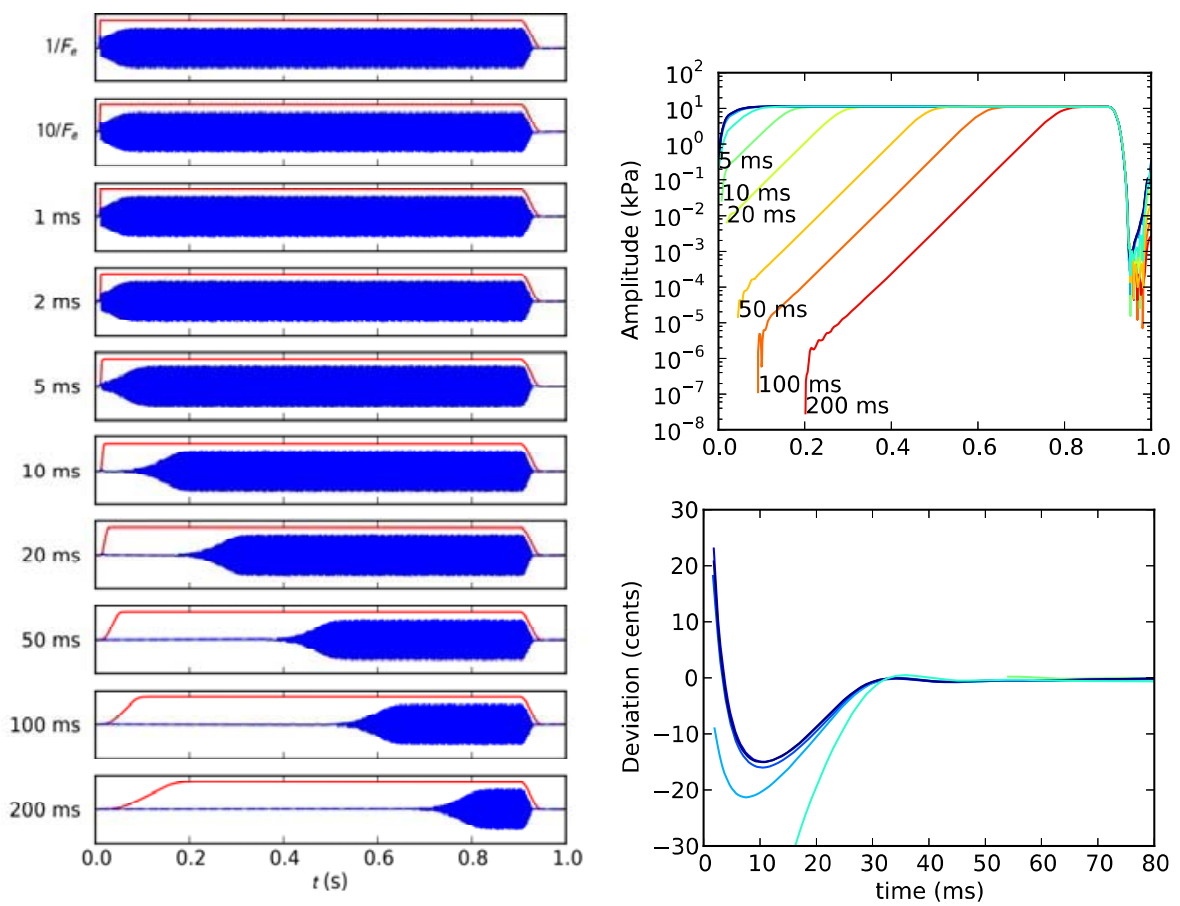

FIGURE 1: Starting transients for various rise time of the mouth pressure. Left: blue curves for input pressure signal, red curve for mouth pressure. Upper right: amplitude of signals. Lower right: oscillation frequency deviation to steady-state frequency. $F_{e}=44.1 \mathrm{kHz}$.

In his $\mathrm{PhD}$ thesis [11], Debut explained why the frequency is not the same during the very short time when the functioning can be regarded as linear, and during the steady-state regime. For the former, the eigenfrequencies differ from the eigenfrequencies of the passive resonator due to the energy supply at the input of the bore, and can be much higher if the sudden increase of the mouth pressure is large. The result shown in Fig. 1 (lower right axes) is in accordance with the work by Debut (Ref. [11], page 109): for the most sudden attack, the instantaneous frequency starts with more than 20 cents above the steady-state frequency. The oscillation frequency then evolve when the harmonics fit into the multimodal resonator, explained as the mode locking phenomenon by Ref. [13].

Concerning oscillations occurring during the first 60 milliseconds, they are due to the analysis method. It is well known that instantaneous frequency estimation on nonstationary multicomponents signals is a tricky problem that combines the choice of the time-frequency analysis window and the speed of variations of amplitude and frequency modulation laws. However several questions can be asked about this frequency variation. Preliminary experimental studies have been done with professional clarinettists. They exhibit a similar tendency, i.e. in general the instantaneous frequency decreases during the first millisecond, but sometimes, it increases. Obviously many other reasons can be sought than the previous one. As an example, the tuning control by the instrumentalist can be the main reason of this behaviour, but this remains to be investigated. Moreover the perceptive effect of this variation is not known, and it is not sure that it is important, because the duration is very short. Further work is needed.

\section{Slurred transients in brass instruments}

The slurred transients are investigated simulating the sound production when increasing and decreasing the natural frequency of the lips of a brass musician. The measured input impedance 
of a Yamaha YTR1335 trumpet has been expanded on 12 modes, with a parametrisation error less than $2 \%$ (see Fig. 2).
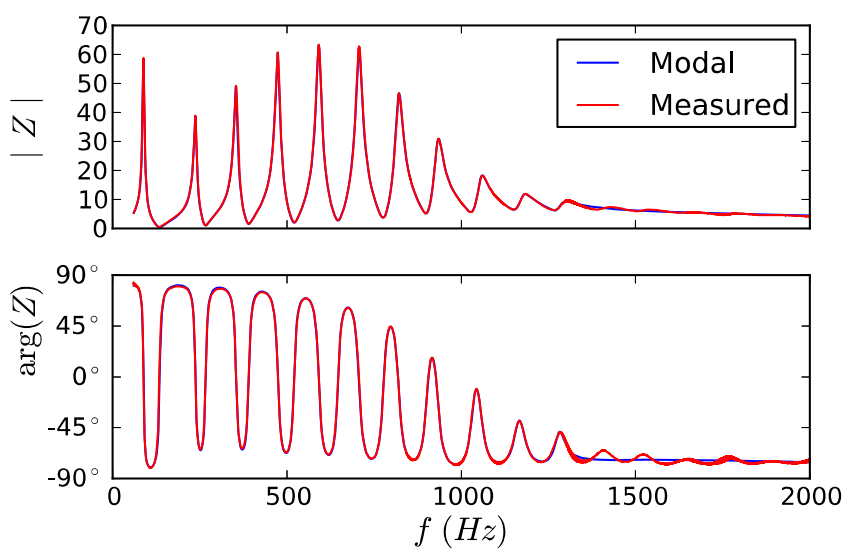

FigURE 2: Measured input impedance of the trumpet and modal expansion.

For a linear decrease from $1 \mathrm{kHz}$ to $100 \mathrm{~Hz}$ of the natural frequency of the lips (modelled as a single d.o.f. oscillator with $q_{r}=0.1$ and $K_{r}=0.8 \mathrm{GPa} / \mathrm{m}^{2}$ ), downwards slurs are observed (see Fig. 3, red curves) when the lips resonance frequency goes too far beyond each of the acoustic resonance frequencies. These changes of regime define playing frequency ranges that are almost centered on the resonance frequencies of the bore $( \pm 50$ cents $)$. On the contrary, upwards slurred transients happen when $\omega_{r}$ crosses one of the bore resonances, i.e. leading to sharper notes. This is what is expected when focusing on oscillation threshold (see e.g. [14]). This difference between the behaviors of the upwards and downwards slurred transients correspond to the feeling of the musician when practising three-notes (up then down, or down then up), requiring important changes on the lips tension. Another consequence is that the musician has to adopt some strategy to overcome the sharper note obtained on upward slur.
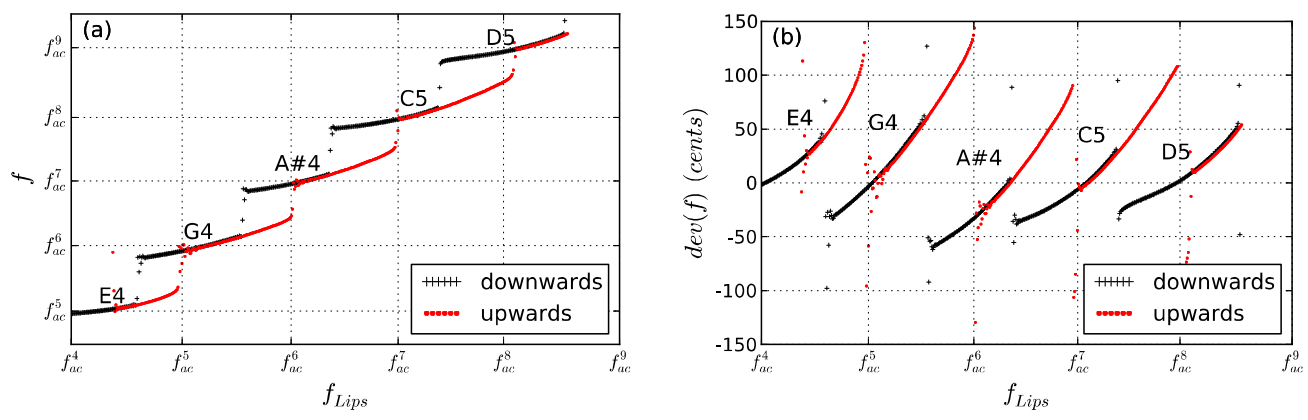

FiguRE 3: Upward (red curves) and downward (black curves) slurs of a trumpet. No valve change, linear variation of $\omega_{r}$. Dotted lines are the acoustic resonances frequencies.

It is also interesting to investigate how the change of regime takes place. In Fig. 4, the lower step of the mouthpiece pressure signal seems to lose stability, like an unstable amplitude modulation until the slur occurs and the amplitude modulation vanishes too, leading to the flatter note. Comparison with the phenomena presented by two players in Ref. [10] requires further investigation on the strategies adopted by these musicians. 

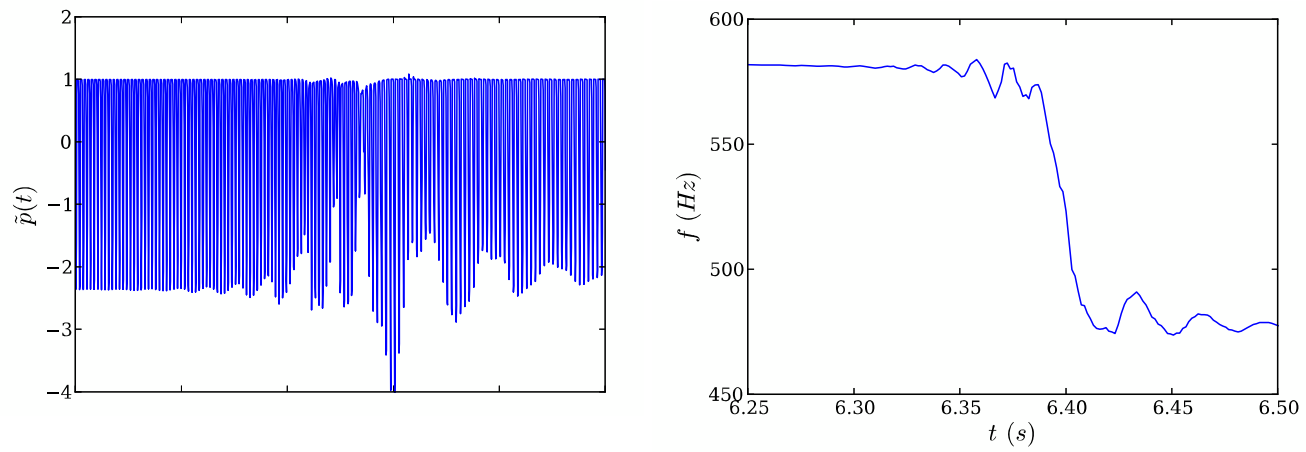

FIGURE 4: Zoom on a downward slur of a trumpet: time-domain signal and instantaneous frequency.

\section{Wah-wah effect}

Last result focuses on the wah-wah effect on the trumpet. Using a rubber plunger mute at several distances from the bell, a series of four input impedance measurements has been expanded onto modes, allowing to define trajectories for each of the poles and residues. Arbitrary 2 s-long sequences of closing and opening of the bell have been modelled as shown in Fig. 5 (left axes, solid curves are trajectories of the modulus of the poles). Simulation for time-invariant characteristics of the lips $\left(\omega_{r}=2 \pi \times 500 \mathrm{~Hz}, q_{r}=0.1, K_{r}=0.8 \mathrm{GPa} / \mathrm{m}^{2}\right)$ lead to sound production with instantaneous frequency oscillating over a range of 20 cents (dashed curve in Fig. 5, left axes). The main effect is visible on the amplitude modulation (Fig. 5, upper right axes), and on the spectral centroï frequency (Fig. 5 , lower right axes), leading to perceptible variations of the loudness and timbre.
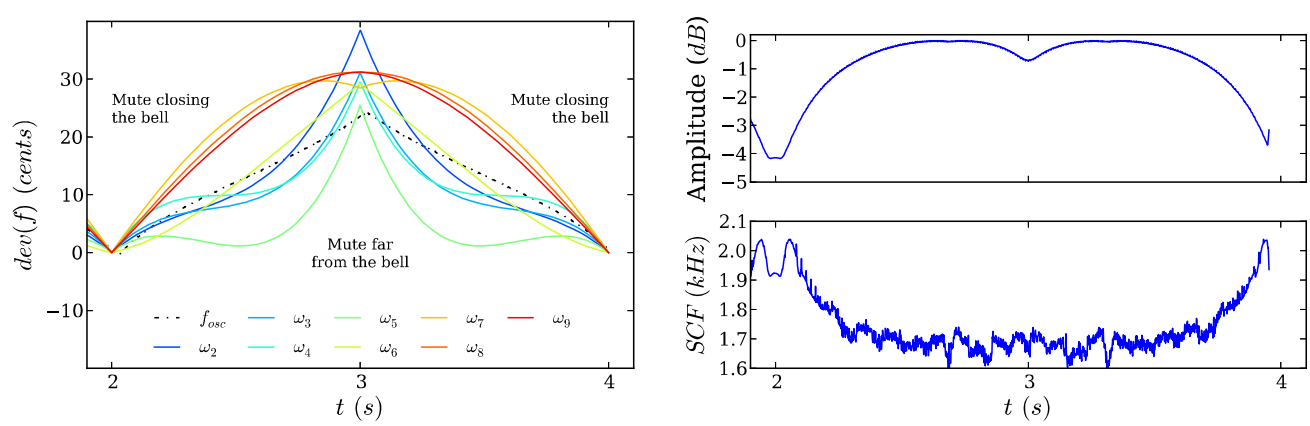

FIGURE 5: Deviation, amplitude and spectral centroïd frequency for the wah-wah effect simulation.

\section{REFERENCES}

[1] J. Antunes, M. G. Tafasca, and L. L. Henrique, "Simulation of the bowed-string dynamicspart 1- a nonlinear modal approach", in Actes du 5ème congrès français d'acoustique, 285$288(2000)$.

[2] R. E. Caussé, J. Bensoam, and N. Ellis, "Modalys, a physical modeling synthesizer: More than twenty years of researches, developments, and musical uses", in 162nd Meet. Acous. Soc. Am. (2011).

[3] A. Barjau and V. Gibiat, "Study of woodwind-like systems through nonlinear differential equations. part ii. real geometry", J. Acous. Soc. Am. 102, 3032-3037 (1997). 
[4] A. Chaigne and J. Kergomard, Acoustique des instruments de musique (Belin) (2008).

[5] A. Hirschberg, J. Kergomard, and G. Weinreich, eds., Mechanics of Musical Instruments, CISM Courses and Lectures No.355 (Springer-Verlag, Wien - New York) (1995).

[6] T. A. Wilson and G. S. Beavers, "Operating modes of the clarinet", J. Acous. Soc. Am. 56, 653-658 (1974).

[7] F. Silva, "Émergence des auto-oscillations dans un instrument de musique à anche simple", Ph.D. thesis, Aix Marseille University (2009).

[8] J. M. Grey, "Multidimensional perceptual scaling of musical timbres", J. Acous. Soc. Am. 61, 1270-1277 (1977).

[9] P. Guillemain and A. Merer, "Rôles du contrôle et du timbre dans la perception du naturel de sons de clarinette", in 10ème Congrès Français d'Acoustique, (2010).

[10] S. Logie, P. Chick, John, S. Stevenson, and M. Campbell, "Upward and downward slurred transients on brass instruments: Why is one not simply the inverse of the other?", in 10ème Congrès Français d'Acoustique, (2010).

[11] V. Debut, "Deux études d'un instrument de musique de type clarinette : analyse des fréquences propres du résonateur et calcul des auto-oscillations par décomposition modale", Ph.D. thesis, Université de la Méditerranée - Aix-Marseille II (2004).

[12] F. Silva, V. Debut, J. Kergomard, C. Vergez, A. Deblevid, and P. Guillemain, "Simulation of single reed instruments oscilations based on modal decomposition of bore and reed dynamics", in Proceedings of the International Congress of Acoustics (Espagne Madrid), (2007).

[13] N. H. Fletcher, "Mode locking in nonlinearly excited inharmonic musical oscillators", J. Acous. Soc. Am. 64, 1566-1569 (1978).

[14] J. S. Cullen, J. Gilbert, and D. M. Campbell, "Brass instruments: Linear stability analysis and experiments with an artificial mouth", Acta Acustica united with Acustica 86, 704-724 (2000). 